\title{
ÓLEOS ESSENCIAIS NO CONTROLE DA FERRUGEM ASIÁTICA DA SOJA Phakopsora pachyrhizi Syd. \& P. Syd.
}

\author{
Essential oils used in the control of asian soybean rust Phakopsora pachyrhizi Syd. \& P. Syd.
}

\author{
Regiane Medice ${ }^{1}$ Eduardo Alves ${ }^{2}$, Rafael Tadeu de Assis ${ }^{1}$, Ronaldo Goulart Magno Júnior ${ }^{1}$, \\ Eloísa Aparecida das Graças Leite Lopes $^{3}$
}

\begin{abstract}
RESUMO
Objetivou-se com este trabalho avaliar o potencial de óleos essenciais na inibição da germinação de urediniósporos de Phakopsora pachyrhizi e na redução da severidade dos sintomas da ferrugem asiática em casa-de-vegetação. O experimento foi conduzido em duas etapas. Na primeira, foram adicionados em placas de Petri contendo $10 \mathrm{~mL}$ de meio de cultura agar-água óleos essenciais de Corymbia citriodora (eucalipto citriodora), Cymbopogon nardus (citronela), Azadirachta indica (nim) e Thymus vulgaris $\mathrm{L}$ (tomilho) nas concentrações $1 \%, 0,5 \%, 1 \%$ e $0,3 \%$, respectivamente para cada óleo. Em placas controles foi adicionado $1 \mathrm{~mL}$ de água. Sobre as placas foram adicionados $100 \mu \mathrm{L}$ de urediniósporos na concentração de $5 \mathrm{mg} / \mathrm{mL}$ de água. As placas foram incubadas por 4 horas a $25^{\circ} \mathrm{C}$ e logo depois avaliada a porcentagem de germinação. Na segunda etapa, em casa-de-vegetação, os óleos foram aplicados nas mesmas concentrações em plantas de soja, cultivares MG/BR46 (Conquista) e Suprema, aos 7 dias antes, 15 e 30 dias depois da inoculação. Os parâmetros avaliados foram incidência e número de pústulas por $\mathrm{cm}^{2}$ de área foliar. Foram também coletadas folhas para preparação de amostras para microscopia eletrônica de varredura (MEV). Constatou-se que os óleos nas concentrações utilizadas inibiram $100 \%$ a germinação dos urediniósporos em meio ágar-água. Em casa-de-vegetação observou-se que todos os óleos retardaram a evolução da doença quando comparado com o controle, sendo que a severidade foi reduzida em média de 34,6 a 60,7\% na cultivar MG/BR46 (Conquista) e de 45,7 a 62, 3\% na cultivar Suprema, em relação ao controle. Nas observações em MEV observou-se que houve murchamento dos urediniósporos, quando tratados com óleo de tomilho. Para os demais tratamentos observou-se apenas redução no tamanho das urédias. Com isso podemos inferir que os óleos essenciais utilizados têm potencial para reduzir o ataque do fungo em plantas de soja.
\end{abstract}

Termos para indexação: Controle alternativo de doenças, óleos essenciais, manejo de doenças.

\begin{abstract}
The objective of this work was evaluating the potential of essential oils in the control of the Asian soybean rust caused by plant pathogen $P$. pachyrhizi. The experiment was carried out in two stages. In the first, in Petri dishes contends $10 \mathrm{~mL}$ of agar-water medium and essential oils from Corymbia citriodora, Cymbopogon nardus, Azadirachta indica or Thymus vulgaris in the concentrations of $1 \%, 0.5 \%, 1 \%$ and $0.3 \%$, respectively for each oil, $100 \mu \mathrm{L}$ of urediniospores were added in the concentration of $5 \mathrm{mg} / \mathrm{mL}$ of water, incubated by 4 hours for $25^{\circ} \mathrm{C}$ and appraised the germination. In second trail in green house, the oils, in the same concentrations, were applied in soybean plants (cultivars MG/BR46 (Conquista) and Suprema) 7 days before and 15 and 30 days after the inoculation. The appraised parameters were presence and number of uredia for $\mathrm{cm}^{2}$ of foliar area. It was also collected leaflets to preparation of samples to Scanning Electron Microscopy (SEM). It was possible to verify that the oils in the used concentrations inhibited $100 \%$ the urediniospores germination in medium agar-water. In green house it was observed that all the oils delayed the evolution of the disease when compared with the control, and the severity of the disease was reduced in average from 34.6 to $60.7 \%$ on the cultivar MG/BR46 (Conquista) and from 45.7 to $62.3 \%$ on the cultivar Suprema in relation to the control. In the SEM it was observed that the urediniospores were withered, on soybean plants where T. vulgaris oil was spread. For the other treatments it was just observed reduction in the size of the uredias. We can infer that the used essential oils have potential to reduce the attack of the $P$. pachyrhizi, agent of the Asian soybean rust.
\end{abstract}

Index terms: Alternative control of disease, essential oils, disease management.

(Recebido para publicação em 2 de junho de 2005 e aprovado em 10 de outubro de 2005)

\section{INTRODUÇÃo}

A soja (Glycine max (L.) Merr.) é uma espécie originária da Ásia, onde vem sendo cultivada há centenas de anos. Graças às suas características nutritivas e industriais e à sua adaptabilidade a diferentes latitudes, solos e condições climáticas, seu cultivo se expandiu por todo mundo, constituindo-se hoje numa das principais plantas cultivadas. Alguns fatores têm limitado o rendimento, a lucratividade e o sucesso da produção de soja, sendo as doenças um dos mais importantes. Mais de 100 delas afetam a cultura, em todo o mundo (HARTMAN

\footnotetext{
${ }^{1}$ Alunos de Agronomia da Universidade Federal de Lavras/UFLA - Cx. P. 3037 - 37.200-000 - Lavras, MG.

${ }^{2}$ Professor Adjunto do Departamento de Fitopatologia - Universidade Federal de Lavras/UFLA - Cx. P. 3037 - 37.200-000 - Lavras, MG ealves@ufla.br

${ }^{3}$ Laboratorista do Departamento de Fitopatologia/DFP - Universidade Federal de Lavras/UFLA - Cx. P. 3037 - 37.200-000 - Lavras, MG.
} 
et al., 1999). Destas, algumas atingem níveis de dano econômico e outras passam despercebidas. Dentre todas as doenças que atacam a cultura, a ferrugem sempre foi considerada como uma das mais importante, devido seu alto potencial destrutivo (ANDRADE \& ARARIPEANDRADE, 2002). A doença é causada por duas espécies de Phakopsora: P. meibomiae (Arthur) Arthur (agente etiológico da ferrugem americana) e $P$. pachyrhizi Syd. \& P. Syd. (agente etiológico da ferrugem asiática), sendo esta última a mais agressiva em plantações de soja (ONO et al., 1992).

Considerando que a ferrugem asiática se trata de uma doença altamente destrutiva, umas das alternativas de manejo ainda é o uso de fungicidas desde que, variedades resistentes ainda não foram desenvolvidas (YORINORI, 2002). Porém, o uso indiscriminado de agrotóxicos pode ocasionar danos ao ambiente, levando ao desequilíbrio ambiental e a seleção de populações do fungo resistentes aos fungicidas. Outra preocupação é quanto aos produtores de soja orgânica, na qual o Brasil vem se destacando como o maior produtor mundial, os quais se viram sem uma alternativa para o controle da ferrugem, uma vez que, a grande maioria dos produtos disponíveis para o controle da doença, não pode ser utilizada. Em função destes fatores, a procura por produtos alternativos que sirvam como defensivos e causem menores danos ao ambiente, sejam estes químicos, biológicos, orgânicos ou naturais, vem crescendo. Poderiam ser enquadrados nesta categoria, os diversos biofertilizantes, as caldas, os agentes de biocontrole e os óleos essenciais (FERNANDES, 2000), sendo que a utilização de óleos essenciais de plantas medicinais tem mostrado resultados promissores no controle de patógenos de plantas (GUIRALDO et al., 2004; SCHWAN-ESTRADA et al., 2003).

Com presente trabalho, objetivou-se avaliar o efeito in vitro e in vivo de diferentes óleos essenciais sobre o fungo $P$. pachyrhizi, agente da ferrugem asiática da soja e verificar o efeito destes óleos sobre o fungo através da microscopia eletrônica de varredura (MEV).

\section{MATERIAL E MÉTODOS}

O experimento foi conduzido nos laboratórios de diagnose e controle de enfermidades, microscopia eletrônica e análise ultra-estrutural e em casa-de-vegetação junto ao Departamento de Fitopatologia da Universidade Federal de Lavras (UFLA), Lavras, MG.
Efeito in vitro de óleos essenciais sobre a germinação de urediniósporos $P$. pachyrhizi.

Para realizar os testes em laboratório, utilizaram-se placas de Petri de plástico com $6 \mathrm{~cm}$ de diâmetro, contendo cada placa $10 \mathrm{~mL}$ de meio de cultura ágar-água. Sobre o agar-água, depois de solidificado foi adicionado um dos óleos, nos seguintes volumes: Corymbia citriodora (Hook.) K. D. Hill \& L. A. S. Johnson (eucalipto citriodora) $1 \mathrm{~mL}$, Cymbopogon nardus (L.) Rendle (citronela) 0,5 mL, Azadirachta indica A. Juss. (nim) $1 \mathrm{~mL}$ e Thymus vulgaris L. (tomilho) $0,3 \mathrm{~mL}$, dando uma concentração final de $1 \%$, $0,5 \%, 1 \%$ e $0,3 \%$, respectivamente para cada óleo. Um mL de água foi adicionado nas placas controles. O óleo foi espalhado sobre a placa com alça de Drigalski e, em seguida, foram depositados $100 \mathrm{~mL}$ da suspensão de urediniósporos na concentração de $5 \mathrm{mg}$ de esporos por $10 \mathrm{~mL}$ de água destilada, a qual foi também espalhada sobre a placa. O experimento foi realizado com três repetições, ou seja, com três placas para cada tratamento. Depois de inoculadas as placas foram levadas para câmara de germinação a $25^{\circ} \mathrm{C}$ no escuro e ao final de 4 horas procedeuse à interrupção do processo germinativo utilizando-se lactoglicerol. Em seguida foi realizada a avaliação pela contagem do número médio de esporos germinados e não germinados, sendo que, para isto a placa foi dividida em 4 quadrantes e contados 25 urediniósporos por quadrante num total de 100 esporos para cada placa. Foram considerados germinados os urediniósporos que apresentavam tubo germinativo com tamanho superior ao do esporo.

\section{Efeito in vivo de óleos essenciais no controle da ferrugem asiática da soja.}

Foi montado um experimento em casa-devegetação, no qual os óleos essenciais utilizados no experimento in vitro foram testados em duas cultivares de soja (Suprema e MG/BR46 (Conquista)). Quatro sementes destas cultivares foram semeadas em vasos plásticos para $3 \mathrm{~kg}$ da mistura de terra, areia e esterco (2:1:2), deixando-se desenvolver duas plantas por vaso num total de 40 vasos. Estes foram distribuídos inteiramente ao acaso. As plantas foram mantidas em casa-de-vegetação e 30 dias após a semeadura, quando as mesmas estavam no estádio V3, $3^{\circ}$ nó trifolio completamente desenvolvido acima do nó unifoliado, realizou-se uma primeira aplicação dos óleos essenciais de citronela, eucalipto citriodora, nim e tomilho, na concentração de $1 \%$ utilizando-se pulverizadores manuais de 1 litro da marca Brudden até o ponto de

Ciênc. agrotec., Lavras, v. 31, n. 1, p. 83-90, jan./fev., 2007 
escorrimento. Uma semana depois procedeu-se a inoculação de urediniósporos de $P$. pachyrhizi proveniente da EMBRAPA Soja, Londrina-PR. Para isto preparou-se uma suspensão de urediniósporos $\left(3 \times 10^{4}\right.$ esporos por $\mathrm{mL}$, contendo $0,1 \mathrm{~mL}$ de Tween $20 \%$ por $10 \mathrm{~mL}$ ) a qual foi aplicada com pulverizador manual de 1 litro. Após o processo de inoculação, preparou-se câmara úmida, onde as plantas foram envolvidas por sacos plásticos transparentes, as quais permaneceram em saturação de umidade por 12 horas para propiciar as condições favoráveis ao desenvolvimento do patógeno. Quinze dias após a inoculação do fungo procedeu-se à segunda pulverização dos óleos essenciais, sendo que, no caso dos óleos de tomilho e citronela a concentração foi reduzida para 0,3 e $0,5 \%$, respectivamente, para evitar problemas de fitotoxidez. Uma terceira aplicação dos óleos foi feita 15 dias após a segunda.

As avaliações da incidência da doença foram realizadas aos 7, 21 e 36 dias após a inoculação, nos períodos da manhã ou final da tarde, enquanto que, as avaliações da severidade foram realizadas aos 21 e 36 dias. As características avaliadas foram presença e número de pústulas por $\mathrm{cm}^{2} \mathrm{de}$ área foliar analisados. Para isto foi avaliado $1 \mathrm{~cm}^{2}$ de cada lado dos folíolos centrais de cada folha inoculada, a qual foi marcada amarando um barbante colorido no pecíolo. Para se marcar a área utilizou-se um pedaço de papel com um orifício de $1 \mathrm{~cm}^{2}$ no centro. Este era colocado sobre o folíolo central e o número de pústulas foi contado.

Na terceira avaliação, os folíolos, depois de avaliados para severidade, foram coletados para preparação de amostras para MEV, cujo objetivo foi o de acompanhar os efeitos dos óleos sobre as estruturas do fungo na planta.

$\mathrm{O}$ experimento foi analisado com base em delineamento inteiramente casualizado, esquema fatorial de $2 \times 8 \times 5$, sendo duas cultivares, 8 repetições (8 plantas), 5 tratamento (envolvendo quatro óleos essenciais e água como controle). Os dados obtidos para severidade foram analisados pelo teste de Scott-Knott, com grau de confiança de $95 \%$ e os de incidência pelo Software Excel.

Preparo e observação de amostras para microscopia eletrônica de varredura (MEV).

A preparação e observação das amostras em MEV foram realizadas seguindo o procedimento de Alves (2004): aos 36 dias após inoculação coletaram-se cinco folíolos, das folhas marcadas com barbante e avaliada a severidade. Os mesmos folíolos foram cortados em pedaços com $0,5 \mathrm{X}$ $0,5 \mathrm{~cm}$, os quais foram imersos em solução fixativa (Karnovisky) pH 7,2 por um período de 24 h. Após este período de fixação o material foi imerso em tampão cacodilato por 3 vezes de 10 minutos em cada imersão e após este processo foi transferido para uma solução de tetróxido de ósmio $1 \%$ em água por 1 hora e subseqüentemente desidratados em uma série de acetona $(25,50,75,90$ (uma vez cada) e $100 \%$ por três vezes) e depois levados para o aparelho de ponto crítico. Os espécimes obtidos foram montados em suportes de alumínio, stubs, com uma fita de carbono dupla face colocada sobre uma película de papel alumínio, cobertos com ouro e observados em MEV LEO EVO 40XVP.

\section{RESULTADOS E DISCUSSÃO}

Efeito in vitro de óleos essenciais sobre germinação de urediniósporos de $P$. pachyrhizi.

Verificou-se que os óleos essenciais de Corymbia citriodora (eucalipto citriodora), Cymbopogon nardus (citronela), Azadirachta indica (nim) e Thymus vulgaris L (tomilho) nas concentrações de $1 \%, 0,5 \%, 1 \%$ e $0,3 \%$, respectivamente para cada óleo interferiram na germinação dos urediniósporos de P. pachyrhizi, como pode ser observado na tabela 1 .

TABELA 1 - Efeito dos óleos essenciais de Corymbia citriodora (eucalipto citriodora), Cymbopogon nardus (citronela), Azadirachta indica (nim) e Thymus vulgaris L (tomilho) nas concentrações de $1 \%, 0,5 \%, 1 \%$ e $0,3 \%$, respectivamente para cada óleo, na germinação de urediniósporos de $P$. pachyrhizi em meio ágar-água.

\begin{tabular}{lcc}
\hline Tratamentos & Não germinados & Germinados \\
\hline Óleo de Eucalipto citriodora & $100 \% *$ & 0 \\
Óleo de Citronela & $100 \%$ & 0 \\
Óleo de Nim & $100 \%$ & 0 \\
Óleo de Tomilho & $100 \%$ & 0 \\
Água & $8 \%$ & $92 \%$ \\
\hline
\end{tabular}

*Media da porcentagem determinada com base no número médio de urediniósporos germinados ou não num total de 100 por placa. Foram avaliadas três placas. 
Estes dados mostram que todos os óleos essenciais estudados apresentam efeito fungistático direto sobre o fungo. $\mathrm{O}$ efeito direto destes óleos sobre fungos já era conhecido (SCHWAN-ESTRADA et al., 2003), entretanto sobre $P$. pachyrhizi é o primeiro relato.

\section{Efeito in vivo de óleos essenciais no controle da ferrugem asiática da soja.}

Levando em consideração a avaliação da incidência da doença com base na presença de pústulas, nos folíolos inoculados, foi possível constatar que apenas o tratamento com óleo de tomilho reduziu a incidência nas três avaliações na cultivar MG/BR 46 (Conquista) e na primeira e segunda avaliações na cultivar suprema (Figura 1A), possivelmente por formar uma barreira à germinação e penetração do fungo na superfície dos folíolos. O óleo de eucalipto citriodora reduziu a incidência apenas na primeira avaliação na cultivar Suprema (Figura 1B). Os óleos de citronela e nim aplicados 7 dias antes da inoculação não apresentaram efeito no processo de germinação e penetração do fungo como o verificado para os outros dois. Entretanto, verificou-se que tais óleos apresentaram efeitos in vitro como visto anteriormente. Isto indica que os óleos de citronela e nim apresentam o baixo poder residual e não estariam mais ativos ou em concentrações necessárias a inibição da germinação quando as plantas foram inoculadas.

Quando se avaliou a severidade da doença com base no número de pústula por $\mathrm{cm}^{2} \mathrm{em}$ ambas as cultivares, verificou-se que todos os óleos aplicados tiveram efeito no controle da doença, de acordo com a análise de variância, porém entre os tratamentos nenhuma diferença pôde ser observada e nem interação dos fatores. Para a cultivar (MG/BR 46) Conquista, a porcentagem de redução da doença na avaliação final variou em média de 34,59 a 60,75 \%. Já para a cultivar Suprema a redução da doença foi de 45,70 a 62,29\% em média (Tabela 2). A expressão visual dos resultados pode ser observada nas Figuras 2, na qual se observa que devido à alta severidade da doença nas folhas de plantas testemunhas (Figuras 2 (1A e 2A))as mesmas se encontravam amareladas, encarquilhadas e em estágio avançado de senescência, enquanto que as folhas de plantas tratadas com óleos essenciais se apresentavam verdes e túrgidas (Figuras 2 (1B-D) e (2B-D)). Foi também observado em casa-devegetação que as plantas tratadas com os óleos mantinham as folhas por um período de tempo maior. No caso da ferrugem da soja foi à primeira vez que o efeito de óleos essenciais na redução da severidade foi constatado em plantas em condições de casa-de-vegetação. Vários trabalhos têm mostrado que estes óleos têm apresentado efeitos sobre outros fitopatógenos in vitro (GUIRALDO et al., 2004; SCHWAN-ESTRADA et al., 2003; ZAMBONELLI et al., 1996), porém, poucos trabalhos haviam mostrado o efeito destes sobre os fitopatógenos em plantas, podendo ser considerado este estudo um dos poucos que mostrou tal efeito e o primeiro no patossistema $P$. pachyrhizi X soja.
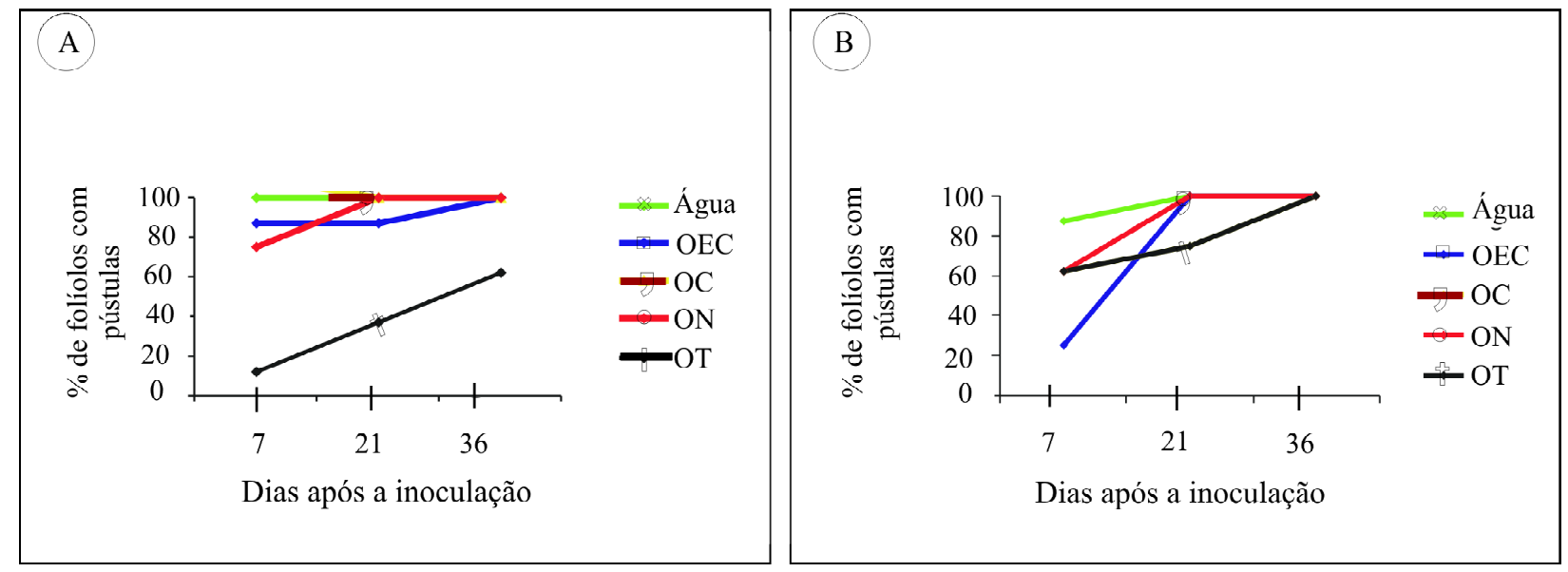

FIGURA 1 - Incidência de pústulas em folíolos de soja dos cultivares MG/BR 46 (Conquista) (A) e Suprema (B) inoculados com P. pachyrhizi e tratados com óleos essenciais em casa-de-vegetação. CEC (óleo de eucalipto citriodora), OC (óleo de citronela), ON (óleo de nim) e OT (óleo de tomilho).

Ciênc. agrotec., Lavras, v. 31, n. 1, p. 83-90, jan./fev., 2007 
TABELA 2 - Severidade da ferrugem da soja (pústulas por $\mathrm{cm}^{2}$ ) e porcentagem de redução da doença nas cultivares MG/BR 46 (Conquista) e Suprema, após a aplicação de óleos essenciais. UFLA - Lavras - MG -2005.

\begin{tabular}{|c|c|c|c|c|}
\hline Tratamentos & $\mathbf{1}^{\mathrm{a}}$ avaliação & $\begin{array}{l}\text { \% de redução da } \\
\text { doença }\end{array}$ & $2^{\mathrm{a}}$ avaliação & $\begin{array}{l}\text { \% de redução da } \\
\text { doença }\end{array}$ \\
\hline \multicolumn{5}{|c|}{ Cultivar MG/BR 46 (Conquista) } \\
\hline Testemunha & $2,57 * \mathrm{~A}$ & 0,00 & $5,81 \mathrm{~A}$ & 0,00 \\
\hline Óleo de E. citriodora & $1,25 \mathrm{~B}$ & 51,36 & $2,72 \mathrm{~B}$ & 53,18 \\
\hline Óleo de Citronela & $1,16 \mathrm{~B}$ & 54,86 & $3,80 \mathrm{~B}$ & 34,59 \\
\hline Óleo de Nim & $1,59 \mathrm{~B}$ & 38,13 & $2,97 \mathrm{~B}$ & 48,88 \\
\hline Óleo de Tomilho & $* *$ & ------ & $2,28 \mathrm{~B}$ & 60,75 \\
\hline $\mathrm{CV}$ & 35,05 & & & \\
\hline \multicolumn{5}{|c|}{ Cultivar Suprema } \\
\hline Testemunha & $3,19 \mathrm{~A}$ & 0,00 & $6,63 \mathrm{~A}$ & 0,00 \\
\hline Óleo de E. citriodora & $1,34 \mathrm{~B}$ & 57,99 & $3,34 \mathrm{~B}$ & 49,62 \\
\hline Óleo de Citronela & $1,06 \mathrm{~B}$ & 66,77 & $3,60 \mathrm{~B}$ & 45,70 \\
\hline Óleo de Nim & $1,15 \mathrm{~B}$ & 63,94 & $3,50 \mathrm{~B}$ & 47,20 \\
\hline Óleo de Tomilho & $0,97 \mathrm{~B}$ & 69,59 & $2,50 \mathrm{~B}$ & 62,29 \\
\hline
\end{tabular}

* Média da avaliação em 8 plantas.

**Planta não avaliada na primeira avaliação devido a leve fitoxidez da dose do óleo aplicada.

Médias com a mesma letra maiúscula na coluna não diferem entre si pelo teste de Scott Knot.

Observações das amostras de folhas de soja do experimento em MEV.

Nas observações realizadas no MEV pode se constatar que nas folhas de plantas provenientes das testemunhas das duas cultivares, MG/BR 46 (Conquista) e Suprema, as urédias eram bem desenvolvidas e com um grande número de urediniósporos, os quais se encontravam túrgidos (Figura 3A e B). Nas plantas tratadas com óleo de tomilho verificou-se que os urediniósporos se apresentavam murchos e em menor número, bem como as urédias eram menores nas condições em que o experimento foi desenvolvido (Figura 3C e D), mostrando um efeito direto do óleo sobre o patógeno. Como verificado por Zambonelli et al. (1996) com outros fitopatógenos, o óleo de tomilho foi capaz de causar degeneração das hifas e extravasamento do citoplasma celular. Tal dano pode ter ocorrido com os urediniósporos neste trabalho, tornando-os inviáveis para a germinação, desde que tem sido comprovado que estes são muito sensíveis. Nos tratamentos com óleo de eucalipto citriodora, citronela (Figura 3 E e F) e nim (Figura não mostrada) não foram observadas alteração na morfologia dos urediniósporos, entretanto as urédias se apresentavam sempre menores. Estes resultados indicam que o óleo de tomilho teve um efeito fungicida direto sobre os urediniósporos, enquanto que para os demais óleos o efeito na redução da doença pode estar relacionado a outros fatores, que deverão ser investigados, como possivelmente a indução de resistência. A redução da severidade da doença nas plantas tratadas com óleos pode ser explicada parcialmente pela presença de urédias de menores tamanho, que irão produzir menos urediniósporos, reduzindo assim a taxa de progresso da doença. Segundo Teuscher (1990), a exploração da atividade biológica de compostos secundários presentes no extrato bruto ou óleos 

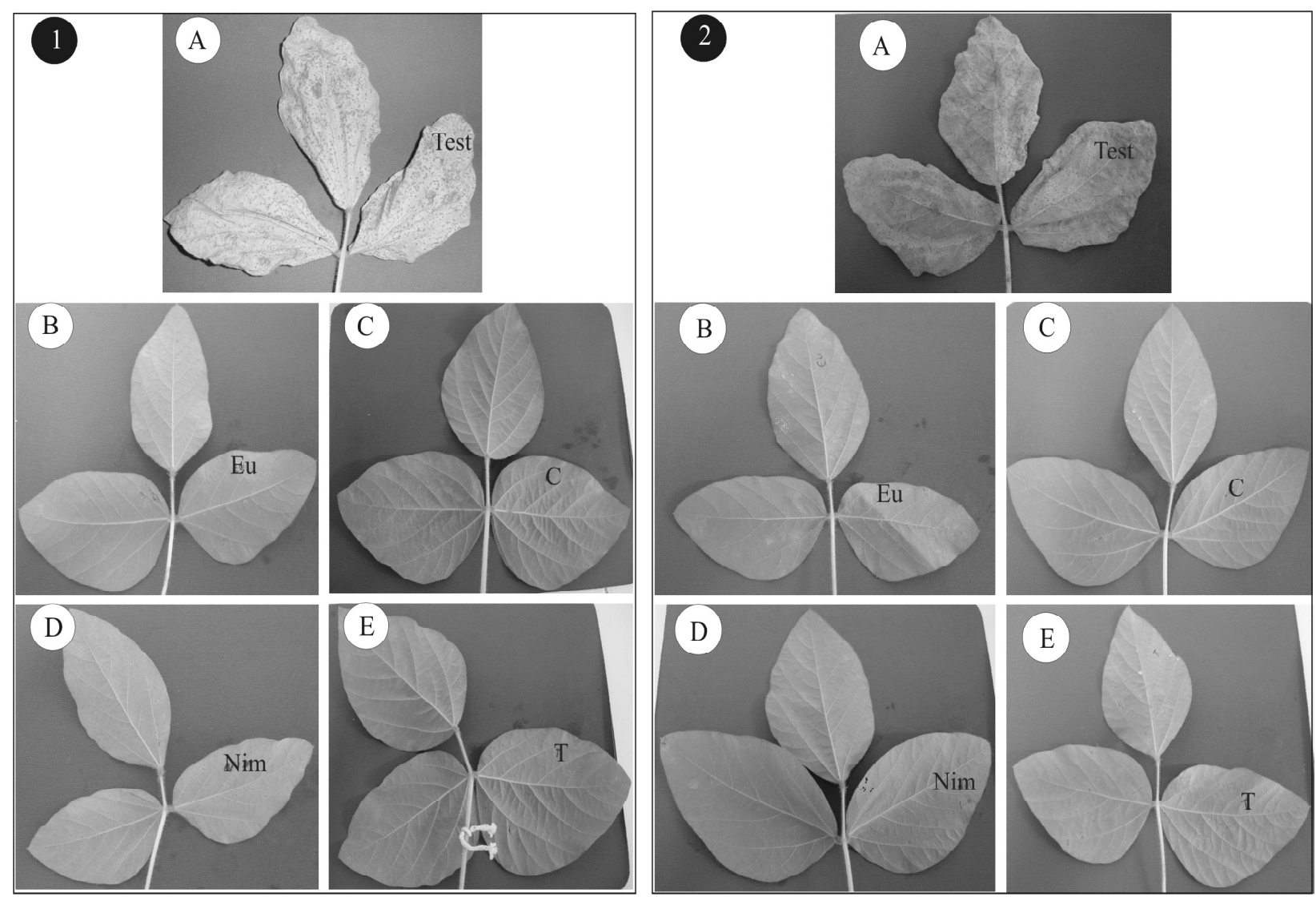

FIGURA 2 - Trifólios de plantas de soja da cultivar MG/BR 46 (Conquista) (1) e Suprema (2) infectadas com Phakopsora pachyrhizi, submetida à aplicação de diversos óleos essenciais. (A) pústulas em folhas que receberam a aplicação de água. (B, C, D e E) trifólios que receberam a aplicação de óleos de C. citriodora (eucalipto citriodora), $C$. nardus (citronela), A.indica (Nim) e T.vulgaris L (tomilho), respectivamente. Trifólios que receberam os tratamentos com os óleos apresentam menor número de pústulas e as folhas permaneceram mais vigorosas e túrgidas, quando comparado com o tratamento feito com água (A).

essenciais de plantas pode se constituir, ao lado da indução de resistência, em mais uma forma potencial de controle alternativo de doenças em plantas cultivadas. Os resultados aqui apresentados são os primeiros obtidos visando ao controle de $P$. pachyrhizi em plantas de soja em casa-de-vegetação e mostram que os óleos testados têm potencial para o controle da doença em cultivos orgânicos e convencionais da soja, entretanto novos estudos estão sendo iniciados para se estabelecer as melhores doses, quais os óleos economicamente viáveis e confirmar quais os mecanismos de atuação dos mesmos no controle do patógeno. 

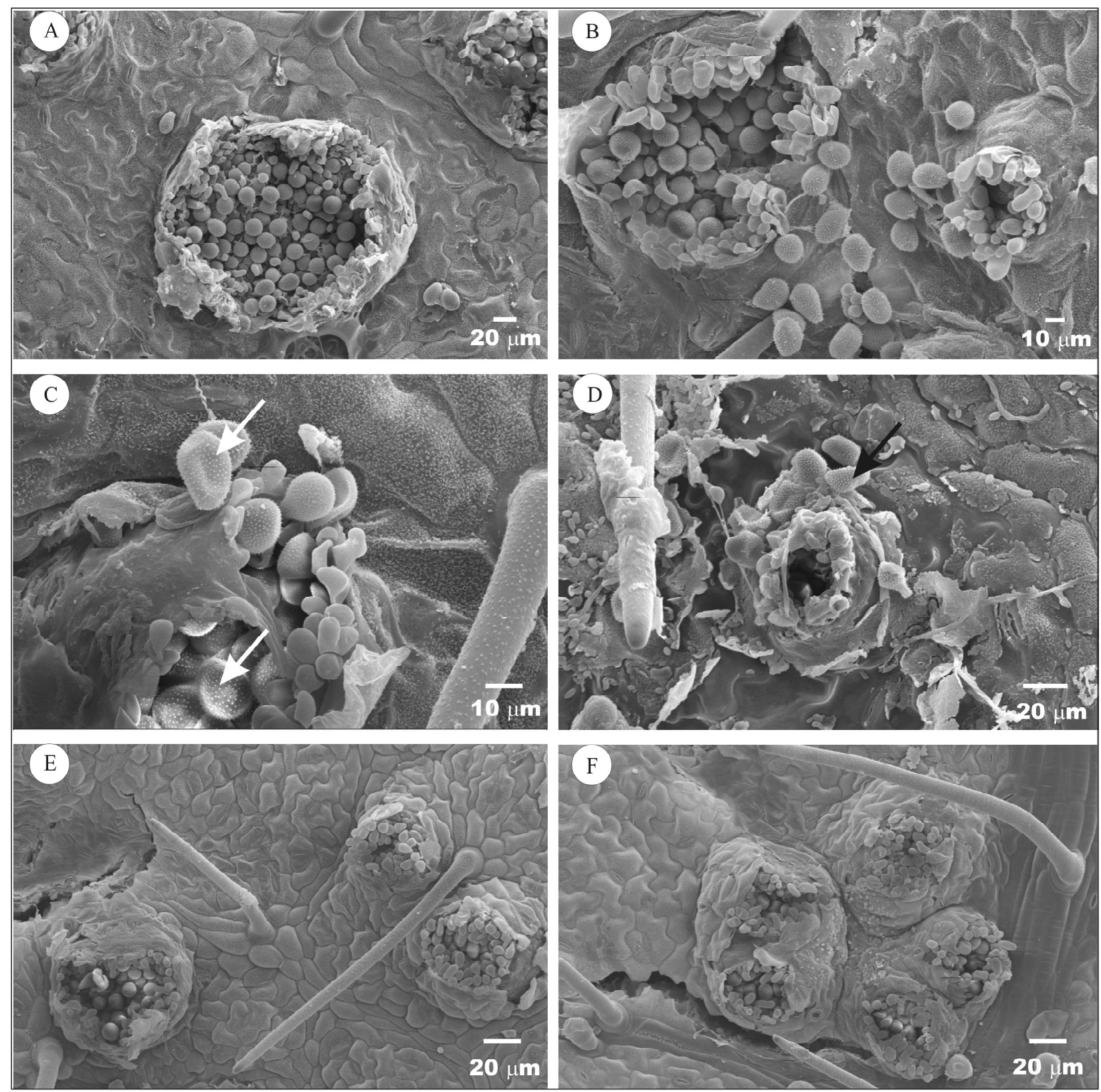

FIGURA 3 - Eletromicrografias de varreduras de folhas de soja infectadas com Phakopsora pachyrhizi, submetida à aplicação de diversos óleos essenciais. (A, C, E e F cultivar MG/BR 46 (Conquista) e B e D cultivar Suprema). (A e B) pústulas em folhas que receberam a aplicação de água. (C e D) pústulas em plantas que receberam a aplicação de óleo de tomilho a $0,3 \%$. Verifica-se que os urediniósporos se encontram murchos (setas). (E) pústulas em folhas que receberam aplicação de óleo de eucalipto citriodora e $(\mathrm{F})$ pústulas em folhas que receberam aplicação de óleo de citronela (cultivar MG/BR 46 (Conquista)). Verifica-se que em D, E e F as urédias são menores que em A e B (eletromicrografias obtidas com o mesmo aumento, como pode ser observado pelas barras). 


\section{CONCLUSÕES}

Pôde-se verificar neste estudo que os óleos de tomilho, eucalipto citriodora, citronela e nim tiveram efeito direto na germinação de urediniósporos de $P$. pachyrhizi e foram capazes de reduzir a severidade da ferrugem da soja em plantas em casa-de-vegetação. A possível forma de atuação do óleo de tomilho foi sobre a germinação dos urediniósporos na folha, na formação de urédias e sobre a viabilidade dos urediniósporos, enquanto que os demais óleos apenas sobre o tamanho das urédias como verificado através das observações em MEV.

\section{REFERÊNCIAS BIBLIOGRÁFICAS}

ALVES, E. Introdução à microscopia eletrônica de varredura. Lavras: FAEPE, 2004. 43 p. Apostila.

ANDRADE, P. J. M.; ARARIPE-ANDRADE, D. F. A. Ferrugem asiática: uma ameaça a sojicultura brasileira. Brasília, DF: Embrapa Agropecuária Oeste, 2002. 11 p. (Circular técnica, 11).

FERNANDES, M. C. A. Emprego de métodos alternativos de controle de pragas e doenças na olericultura. In: CONGRESSO IBERO-AMERICANO SOBRE UTILIZAÇÃO DE PLÁSTICO NA AGRICULTURA, 2.; SIMPÓSIO LATINO-AMERICANO DE PRODUÇÃO DE PLANTAS MEDICINAIS, AROMÁTICA E CONDIMENTARES, 1., 2000, São Paulo, SP. Horticultura Brasileira, Brasília, v. 18, p. 110-112, 2000. Suplemento.
GUIRALDO, N.; AMBROSANO, E. J.; MENDES, P. C. D.; ROSSI, F.; AVÉRALO, R. A. Controle de doenças em sistema agroecológicos. Summa Phytopathologica, Botucatu, v. 30, n. 1, p. 153-156, 2004.

HARTMAN, G.; SINCLAIR, J.; RUPE, J. Compendium of soybean diseases. Saint Paul: APS, 1999. 128 p.

ONO, Y.; BURITICA, P.; HENNEN, J. F. Delimitation of Phakopsora, Physopella and Cerotelium and their species on Leguminosae. Mycological Research, London, v. 96, n. 10, p. 825-850, 1992.

SCHWAN-ESTRADA, K. R. F.; STANGARLIN, J. R.; CRUZ, M. E. S. Uso de plantas medicinais no controle de doenças de plantas. Fitopatologia Brasileira, Brasília, v. 28, p. 5456s, 2003. Suplemento.

TEUSCHER, E. Pharmazeutische biologie. Braunschweig: Vieweg, 1990.

YORINORI, J. T. Situação atual das doenças potenciais no Cone Sul. In: CONGRESSO BRASILEIRO DE SOJA E MERCOSOJA, 2., 2002, Foz do Iguaçu. Anais... Foz do Iguaçu: [s.n.], 2002. p. 171-186.

ZAMBONELLI, A.; D'AURELIO, A. Z.; BIANCHI, A.; ALBASIN, A. Effects of essential oils on phytopathogenic fungi in vitro. Journal of Phytopathology, Berlin, v. 144, n. 3, p. 491-494, 1996. 